\title{
Research on Emotional Control of Students in Basketball Teaching in Colleges and Universities
}

\author{
Xiongwei , Zuo Xia Zen \\ Changsha Medical University, Changsha, Hunan, 410219
}

Keywords: Emotional Control, Students, Basketball Teaching, Colleges and Universities

\begin{abstract}
Basketball teaching is a complex and varied process, all kinds of factors will stimulate the students to change the mood, affecting the teaching effect. According to the characteristics of students emotional development and changes, the teachers should adopt a variety of targeted control measures to induce students to have a positive emotional experience, so as to achieve teaching results.
\end{abstract}

\section{Introduction}

Basketball lessons as the main content of physical education, by the majority of students love. But because of the characteristics of basketball itself and the subjective and objective factors in teaching, resulting in students in the learning process of emotional changes, and thus directly affect the quality and effectiveness of teaching. Therefore, in the process of basketball teaching, teachers according to the actual situation of student changes, combined with the characteristics of the basketball class itself, to take appropriate control measures and effective teaching methods, to improve the quality and effectiveness of basketball lessons to improve students' basketball Special technology has a positive effect. Emotion is a kind of psychological process of human being, which is a kind of expression of emotion. It can be divided into two types of emotion (negative factor) emotion and power (negative factor) emotion. In the course of basketball teaching, there are many factors that affect students' mood changes. Teachers should use the appropriate way to weaken the impact of reduced power, to create a situation of power to increase power, strengthen the power of empowerment, to stimulate students' enthusiasm for learning, to achieve good teaching results. In the teaching of basketball, there are two main factors that affect students 'mood changes: one is the change of students' mood caused by the characteristics of basketball itself. Basketball sports action content is rich, flexible combination of action, different, simple and varied, student mood changes. When the teaching content is simple, the action is relatively easy to grasp, the students are prone to pride and complacency, learning is not serious, practice perfunctory; when the teaching content is slightly more difficult to master difficult to complete, students prone to frustration do not want to learn to resist practice. In addition, in the teaching process, when the teachers organize students to conduct a comprehensive exercise or teaching competition, because of basketball tactical change, strong offensive and defensive, students often lose points and conceded on the mistakes, contradict each other caused by the decline in emotional decline, or due to the lead temporarily lead to generate excitement, rising power. Second, due to the students themselves caused by emotional changes. Some students learn the purpose of fuzzy or even wrong, that physical education cannot be on; learn to learn bad does not matter, up to learn a few actions to cope with the exam. Such motivations tend to transform students' emotions from the power of learning that has just been generated to the negative emotions of negative emotions. Some students have good physical condition, there is a certain basis of basketball technology, in learning, since the very high, that teachers, but so; practice, to cope with things, do not seek further. There are some students of their own poor quality, less athletic skills, learning lack of confidence, not practice, there is a strong inferiority complex.

\section{The Students' Emotions and the Impact on the Quality of Teaching}

In the basketball lesson, students in the classroom learning mood is the students engaged in 
basketball teaching activities generated when the excited state of mind. It can be said that the student's learning emotions arise from practical activities, and directly affect the practice of the conduct, it is a complex human psychological activities. As the emotional generation is accompanied by changes in physiological function, happy positive emotions accompanied by good psychological function, it can make students quick thinking, action coordination, so as to achieve good teaching results; the contrary, restless, nervous negative emotions will inhibit the physiological function of benign activities, so that students unresponsive, action out of control, inattention, so that the teaching effect decreased significantly. Therefore, in the basketball class teaching, teachers should be based on teaching content, choose a reasonable teaching methods, regulation of good students learning mood, so that both to ensure the effect of practice, but also improve the quality of teaching.

Emotion is generated by people in some kind of activity, it is a kind of psychological activity and emotion is a form of expression. Basketball general course student mood with distinct, diverse, volatile three major features. Learning complex and failed alternation, the complexity and change of basketball techniques and tactics, as well as the changing physical function of students, so that students behave a variety of complex, complex, but with other emotions can still be divided into positive and negative two types, Under certain conditions can be transformed into each other. Here, according to years of teaching practice, the students emotional changes from the main and objective aspects of specific analysis.

Objective Factors Cause Emotional Changes. The emotional changes caused by the project itself. Basketball technical action is more complex, from the basic technology to tactics, rich in content, difficulty, easy to cause students to change the mood. If the content of teaching materials is complex, the action is difficult, master the action is slow, and even cannot complete the action, often expressed as loss of confidence, depression, low-key, low-key do not want to practice and other emotions.

Teaching competition caused by emotional changes. Basketball game is a group of activities, the scores of the game scores often lead to emotional changes, once cannot afford a pass cannot organize effective attack, with bad, mutual complaints, low morale, playing emotional ball; Be handsome, when you win, morale is high. Intense confrontation, so that students emotional expression for a while excited, while nervous, while low, with the score changes, the student's mood also showed an unstable state of volatility.

Climate-induced changes in mood. Basketball teaching to outdoor teaching mainly, therefore, affected by climate change is also greater. For example, in the winter, the climate is dry and cold, students are often reluctant to activities; in the summer, the climate is hot, students often produce fear of fear of sweating negative psychology.

Subjective Factors Caused by Emotional Changes. The impact of learning motivation on the students the motivation of learning is correct, whether the purpose is clear is the main reason for students to change the mood. By talking to the students, it was found that some students did not have enough clarity to study, but to learn how to cope with the exams, rather than as a skill to master, the practice is often not enough emotion.

Personality characteristics and physical condition affect the emotional characteristics of students and physical condition, but also affect the emotional changes in the reasons. Some students think that their physical condition is good, the quality is good, the technical level is slightly higher, their own estimate is too high, complacent, there is pride and complacency; there are some students always think their poor quality, athletic ability weak, born stupid, to learn action lack of confidence, not to take the initiative to consciously learn, resulting in inferiority complex, affecting the enthusiasm of learning.

The degree of technical mastery of the impact of the students themselves on the degree of technical control also have a certain impact on emotions. Through observation, it is found that students who master the technology and have a positive effect on learning, and students who are slow and ineffective in technical action are depressed and prone to boredom, and sometimes even pass to cope with the teacher the practice of a few, but the teacher will not pay attention to lazy 
slack.

\section{Students Negative Emotions Control Measures of the College Basketball Lesson Teaching}

Students' individual differences produce negative emotions and control measures. In the implementation of basketball special physical education teaching, due to the students to participate in the practice of sports activities and different motives, some physical fitness, special skills poor students on the lack of ideological teaching basketball prepared, so in the actual teaching process, Teaching technical action difficult to understand, fail to meet the requirements of the teacher's practice. Because this part of the students basketball skills are poor, in practice when the action is not coordinated, often by other students ridiculed, some skilled students do not cooperate with the practice. When these students encounter difficulties and setbacks, will produce a variety of negative learning mood. Therefore, the teacher first from the students to solve the fundamental ideological problems, so that students correctly understand the purpose of physical education, and establish the correct learning motivation and goals.

Teaching practice content and means of unreasonable negative emotions and control measures. In the course of basketball teaching, teachers can reasonably and scientifically arrange and arrange the contents and tasks of each class is to ensure the quality of students practice. If the content of the exercise is less or less monotonous, it will reduce the students' interest in practice. Some students with better skills are not active, have no concentration, feel bored, and even do not want to practice. Shake the motivation of these students; if the practice content is too much, the task is too large, too long a number of poor technology students will have fear, basketball lesson aversion or aversion to teachers. Therefore, in the course of basketball teaching, teachers should analyze the actual situation of each student, according to the content of teaching materials to choose a reasonable teaching methods, to adopt flexible and flexible means of practice, in order to improve students' interest in practice, to stimulate positive emotions.

Negative emotions caused by student personality and control measures. Everyone has his own personality, can make people add positive and positive emotions; on the contrary, weaker personality, easy to produce depression, low self-esteem negative emotions. Teachers should always remind students to maintain a normal state of mind, the correct treatment of the experience encountered in the setbacks and failures, to determine the healthy goals of the struggle, firm belief, to learn to self-regulation. In addition, teachers should correctly guide students to play their own strengths, and strive to enhance the confidence of students to make their own ability to believe.

Site equipment and climate conditions caused by students' negative emotions and control measures. In the teaching of basketball, the environment of the site, the old and new conditions of the equipment and the climatic conditions, will have a certain impact on the changes in student mood. In a good environment for teaching students will have a strong desire to practice, students exercise feel comfortable, proactive, so as to improve teaching effectiveness. In the harsh environment for teaching, it will greatly affect the students' practice of emotions. This requires teachers to clarify the purpose of physical education, and take the initiative to create a good teaching environment.

Negative emotions and control measures caused by the teacher's image and the relationship between the students. People's mood changes can affect relationships. For example, in the basketball lesson, if the teacher is depressed, the students show disgust, anger, the students will be afraid of the teacher and hate bad mood; students are not harmonious, there is a conflict, teaching cannot be done normally. Therefore, teachers must first regulate their own moral cultivation, so that teachers for the table. In the basketball lesson, students 'mood changes are complex and diverse, and various internal and external factors will make the students' mood change. The quality of basketball teaching quality and student classroom mood changes have a great relationship, a direct impact on teaching effectiveness. Teachers in the judgment of students to produce a negative emotions, from the characteristics of teaching materials, teaching forms, teaching environment, their own teaching and other aspects, combined with the students' sports base, gender differences, personality characteristics of a comprehensive consideration to find out the students emotions change the 
different reasons, purposeful, planned, targeted to develop appropriate control measures. So as to enable students to maintain a good and orderly emotional state throughout the teaching process, so as to improve the quality of basketball teaching.

\section{Conclusion}

We should educate students to correct their attitude, clear the purpose of learning, rational organization of teaching, using a variety of ways to active classroom atmosphere, in order to stimulate students' enthusiasm for learning to mobilize the enthusiasm of students. And we should also play the students' subjective initiative, so that students can actively cooperate with teachers to complete teaching tasks, and also exercise the physical quality, psychological quality and collectivism of students to achieve the teaching effect.

\section{References}

[1] Jin Hongwei. How to prevent sports accident injuries in public physical education in colleges and universities [J]. Test Weekly, 2008.12(3) : 62-67.

[2] Ding Yingjun, Zhu Ji. Injury attribution and legal protection of accidental injury in school sports [J]. Journal of Henan Education Institute, 2006.(5):45-48.

[3] Zhou Aiguang. Research on the current situation of school sports insurance in Japan [J]. China Sports Science and Technology, 2005.3(2):123-125.

[4] Qu Junyi.Improvement of Basketball classroom teaching mood research [J]. Finance Education Research, 2006. 12(2):35-38.

[5] Yan Ning, Mao Rongjian, Mao Zhixiong. Physical activity and physical effect of physical exercise [J]. Journal of Beijing Sport University, 2003 (01):89-95.

[6] Qin Wei Feng. Juvenile athletes emotional health problems [J]. Fujian Sports Science and Technology, 2002 (03).34-37. 